\title{
Management of the Soil Environment in High Tunnels
}

\author{
Adam Montri ${ }^{1}$ and J.A. Biernbaum
}

ADDITIONAL INDEX WORDS. organic matter, certified organic management, moisture, fertility

Summary. High-tunnel soil, water, and fertility management can be achieved using a wide range of approaches from polyethylene film-mulched, drip-fertigated beds to certified organic management based on maintaining high soil organic matter (SOM) content. Soil management techniques are discussed in relation to the high tunnel structure used and the length of the growing season, site preparation, soil health, SOM, irrigation water quality, and fertility, with a focus on certified organic management.

\section{Perspective}

The term "high tunnel" is currently used to describe structures ranging from continuous, multiacre, single-layer polyethylene film, threeseason covers to stationary or mobile individual coldframe greenhouses with single- or double-layer inflated polyethylene film. They can be used for season extension and 12-month production. Seasonal versus 12 -month covers and the number of crops per year define the degree of variance in soil management practices from standard field production methods. Our experience includes year-round vegetable production with an emphasis on winter production at Michigan State University and season extension of warm-season crops at Pennsylvania State University. Based on these experiences, key high-tunnel soil management issues include site preparation, soil health, soil moisture, and soil fertility. Our focus is on methods suitable for organic certification.

\section{Site preparation}

If the soil is not already in production, key objectives for site preparation include removal of existing groundcover, reduction of the weed seed bank, increasing soil organic matter (SOM) and fertility, and if necessary, grading and adjusting the slope for rain water removal. It is recommended that site and soil preparation begin 1 year or more before construction. A site larger than the

Department of Horticulture, 288 Plant and Soil Sciences Building, Michigan State University, East Lansing, MI 48824

${ }^{1}$ Corresponding author. E-mail: admontri@anr.msu. edu. dimensions of the high tunnel will facilitate a perimeter around the structure, which helps to exclude undesired vegetative growth and burrowing animals. Groundcover removal, increased SOM and fertility, and decreased weed seed and soil compaction can be achieved by tillage, mulching, sheet composting, and cover crops (Sarrantonio, 1994).

For four-season structures built on sites with slow drainage (clay subsoil), an elevated site or perimeter drain tile are necessary to prevent interior flooding. About $1800 \mathrm{gal}$ of water are displaced for each 1 inch of rain (Blomgren and Frisch, 2007). If rain is not moved away from the structure, moisture is likely to enter the high tunnel, causing soil saturation and subsequent poor plant growth and performance, particularly during the winter months. For threeseason structures, site preparation needs to include ways to manage water runoff and infiltration because there are no gutters at the eaves to laterally move rain water away from the structure.

\section{Soil health and organic matter management}

While crop production can be managed using fertigation to provide water and soluble nutrients and fungicides to manage soilborne pathogens, another approach is to focus on long-term soil health, based on SOM management and maintenance of the soil food web. Increased SOM has been shown to improve physical, chemical, and biological soil quality indicators, such as water absorption and retention, soil biological activity, cation exchange capacity, nutrient availability, microbial biomass, carbon and nitrogen pools, and disease suppression (Gaskell et al., 2000). To achieve success and reduce the potential for soil exhaustion, a balance of active, short-term, and long-term organic matter is recommended (Magdoff and van Es, 2000).

Soil health is critical due to the premium value of space in the high tunnel. In addition, the diversity of cropping systems, ranging from perennial trees and berries to singleseason annuals to three to five sequenced crops per year, makes it difficult to provide specific recommendations. Inherent characteristics of high tunnels pose some unique challenges to SOM management. The elevated soil temperatures, possibly decreased moisture levels, and the lack of soil freezing with fourseason production are expected to alter the rate of biological activity. It is not clear if this results in SOM depletion or a shift from short-term to long-term SOM. To our knowledge, seasonal soil respiration data in high tunnels are not available. It has been proposed that in high tunnels with biologically active soil and available SOM, soil respiration can provide carbon dioxide that may positively impact crop growth or at least prevent midday photosynthetic depression of carbon dioxide levels when ventilation is limited (Moore, 2000).

We have experience using buckwheat (Fagopyrum esculentum), ryegrass (Lolium multiflorum), and hairy vetch (Vicia hirsuta) as cover crops in high tunnels. In a year-round

\begin{tabular}{lllc}
\hline $\begin{array}{l}\text { Units } \\
\begin{array}{l}\text { To convert U.S. to SI, } \\
\text { multiply by }\end{array}\end{array}$ & U.S. unit & SI unit & $\begin{array}{l}\text { To convert SI to U.S., } \\
\text { multiply by }\end{array}$ \\
\hline 0.3048 & $\mathrm{ft}$ & $\mathrm{m}$ & 3.2808 \\
0.0929 & $\mathrm{ft}^{2}$ & $\mathrm{~m}^{2}$ & 10.7639 \\
0.0700 & $\mathrm{ft}^{3} /$ acre & $\mathrm{m}^{3} \cdot \mathrm{ha}^{-1}$ & 14.2913 \\
3.7854 & gal & $\mathrm{L}$ & 0.2642 \\
25.4 & inch $(\mathrm{es})$ & $\mathrm{mm}$ & 0.0394
\end{tabular}


production system, the time required for the high tunnel to be out of cash crop production and the challenges of management and incorporation within the structure support the use of other strategies to increase SOM, particularly compost application. Compost applications combined with contributions of belowground biomass from three to five crops within the high tunnel function in similar ways to cover crop usage in standard field situations. Most notably, they contribute organic matter, which in turn provides the myriad of benefits previously mentioned. Compost application is favored for SOM increases in the high tunnel because a crop may be planted immediately following application. It is practical to remove a crop, apply compost, and seed or transplant a new crop within a $1-h$ period, minimizing the time when growing space is left unoccupied.

Compost at the Michigan State University Student Organic Farm (MSU-SOF) is applied in the high tunnels before the fall crop at a rate of $\mathrm{l} \mathrm{ft}^{3}$ per $20 \mathrm{ft}^{2}$ of production area, or $\approx 2178 \mathrm{ft}^{3} /$ acre equivalent. The composts used are mostly carbon based and contain limited to no animal manures, as the lack of leaching within the structure does not allow for removal of excess nutrients and soluble salts. Individual beds at the MSUSOF are prepared in a manner similar to that described by Coleman (1998). Preparation involves a three-step process that includes the use of a broadfork for lifting and aerating the soil, a three-tine claw for breaking up larger soil aggregates, and an Austrian-style hay rake to remove excess debris and spread compost over the soil surface. Compost is left on the surface to facilitate water absorption, to prevent crusting during seed germination, and to initially keep the immediately available nutrients at the surface. Between crops, the soil is prepared in a similar manner, though no compost is incorporated until the following fall. Broadfork use between crops allows the compost to penetrate the soil more deeply after readily available nutrients have been used.

Future research needs in the area of SOM management include compost application rates and types of compost based on the cropping system (perennial or annual) and crop rotation. SOM cycling under protected cultivation could also prove to be an interesting research topic, particularly between three- and four-season production systems. An investigation of soil respiration and the microbial community with varying soil moisture could also improve soil knowledge and management strategies.

\section{Soil moisture and irrigation}

A key advantage of high tunnel production is the exclusion of excess rainfall, which can detrimentally influence product quality. In addition, the ability to more closely manage soil moisture and subsequent nutrient availability increases opportunities for successful crop production. In drip irrigation, water-soluble fertilizer concentration and the water application rate influences fertility by altering the application rate, while in an organic system, soil moisture is a major regulator of soil biological activity and subsequent fertility. Irrigation techniques will vary by location, soil type, production method, and time of year. Common systems include drip and overhead, but subirrigation can also be used. With continuous cover, if irrigation is not sufficient to reach at least $0.5 \mathrm{~m}$, the rooting zone may become limited. What appears to be properly irrigated soil on the surface has the potential to be dry below. Digging a hole to sample soil moisture is a recommended control that achieves quick results.

Drip irrigation is preferred for its efficiency and labor cost savings, as well as its ability to maintain dry foliage. For small systems, a pressure regulator may be used to decrease water pressure to prevent drip irrigation line damage. Overhead irrigation may consist of microsprinklers or another sprinkler system, as well as hose and breaker applications. Throughout much of the midwestern United States, limestone aquifers produce water with high hardness, alkalinity, and iron, which often blocks drip emitters and stains polyethylene film, resulting in decreased light transmission. Wand and breaker application, while time consuming, is used for winter production in northern climates where water may not drain from drip irrigation lines and sprinkler lines may freeze. Installation of frost-free hydrants inside the high tunnel in northern climates is necessary, and hoses are drained after each use in winter months.

Future research areas related to soil moisture include: the effects of soil moisture on fruit quality, and heat and cold tolerance and heat retention in the winter. Observations at the MSU-SOF lead us to believe that elevated soil moisture may mitigate high temperature stress, while lower soil moisture may contribute to plant survival at low or freezing temperatures. In addition, the effect of soil moisture on relative humidity within the high tunnel poses several researchable questions, especially in relation to heat retention and light transmission. Increased relative humidity causes condensation to form on the interior of the plastic film. This condensation functions in a way similar to cloud cover, thereby making the interior of the high tunnel warmer. However, this condensation also reduces light transmission. The effect on heat retention and light transmission in relation to ventilation and interior plant cover (polyethylene vs. frost fabric) has not been characterized.

\section{Fertility management}

Intensity, capacity, availability, and balance characterize soil fertility. These components can be managed by feeding the plant or feeding the soil. When feeding the plant, nutrient application is based on replacing the nutrients removed by the crop. It can be achieved by granular application or by continuous or intermittent fertigation through a drip irrigation line. This approach, similar to hydroponics, treats the soil as a medium to which fertilizers are added. In contrast to this is the approach of feeding the soil. When feeding the soil, organic matter is managed to maintain soil microorganism activity and the soil food web so that nutrients become available through mineralization.

In the protected high-tunnel environment, overfertilization has the potential to result in reduced plant health and increased susceptibility to plant pathogens and insect damage (Magdoff and van Es, 2000). Because rainfall is excluded in these structures, nutrient leaching is minimized and lower fertility application rates may be more successful compared with standard field rates. 
Research questions related to soil fertility include the efficacy of fertilizer applications in the absence of leaching and how fertilizer application rates in high tunnels differ from field recommendations. In addition, production under decreased temperatures and light levels has the potential to lead to nitrate accumulation in cold-tolerant leafy greens. Soil and tissue nitrate tests could provide insight into fertility management for winter production, including a comparison of water-soluble fertilization versus organic management.

For fertility management in biologically based high tunnel systems, the effects of organic matter and soil moisture management are key points. Based on organic farmers' recommendations and our experiences, compost applications appear to be the most effective and efficient means of adding and raising SOM in high tunnels. Due to rain exclusion and the absence of leaching in these structures, animal manure-based composts should be avoided to minimize excessive soluble salt and nutrient levels. High-carbon compost made from straw, leaves, or wood shavings combined with hay provides needed nutrients without adding excessive nitrogen or soluble salts.

\section{Conclusion}

Soil management and the maintenance of soil health in high tunnels is the integration of soil, water, and nutrient management. The exclusion of rain and leaching for part or all of the year in these structures, rapid plant growth due to elevated temperatures, and the effect of nonfreezing soil conditions on soil biology in the case of four-season production are several important factors to consider when developing a management plan and addressing long-term soil health in high tunnels.

\section{Literature cited}

Blomgren, T. and T. Frisch. 2007. High tunnels: Using low-cost technology to increase yields, improve quality, and extend the season. University of Vermont Center for Sustainable Agriculture, Burlington.

Coleman, E. 1998. The winter harvest manual: Farming the backside of the calendar. Four Seasons Farm, Harborside, ME.

Gaskell, M., B. Fouche, S. Koike, T. Lanini, J. Mitchell, and R. Smith. 2000. Organic vegetable production in California: Science and practice. HortTechnology 10:699713.

Magdoff, F. and H. van Es. 2000. Building soils for better crops: Sustainable agriculture network handbook series book 4. Sustainable Agriculture Publications, Burlington, VT.

Moore, S. 2000. Economic mini-farming under a passive solar greenhouse. Proc. Soil Food People Conf., Davis, CA, 2729 Mar. 2000. p. 116-121.

Sarrantonio, M. 1994. Northeast cover crop handbook. Rodale Institute, Emmaus, PA. 